\title{
As vozes de Enfance de Nathalie Sarraute
}

Renato de Mello**

RESUMO: Estudo da obra autobiográfica de Nathalie Sarraute - Enfance - no qual se analisam dois aspectos singulares no contexto das escritas da memória: a utilização dos tropismos como estratégia memorialística e a presença de um sujeito fragmentado, expondo-se numa estrutura dramática, composta de duas vozes.

Enfance, ' de Nathalie Sarraute, inicia-se, inesperadamente, com um diálogo que apresenta uma decisão já tomada sobre um projeto problemático: a possibilidade de produzir um texto autobiográfico.

A frase banal de abertura do texto, dirigida à narradora - Tu vas vraiment faire ça? Evoquer tes souvenirs d'enfance... (E, 7) é o suficiente para provocarlhe uma reação em cadeia. A narradora, interpelada, questionada em seu projeto, responde ao ataque, apresentando um desejo impulsivo de escrever tal texto através da mobilização de lembranças da infância, de viagens, de leituras, de toda uma sequiência de palavras e ações incompletas.

Com grande número de travessões, aspas e reticências, a autora refere-se, de início, a algo que ainda não tinha sido dito ou, mesmo, escrito: - Tu vas vraiment faire ça?... (E, 7 - grifo nosso). A obra mostra-se, portanto, iniciada, sem começo, e também não terá fim, já que exibe possibilidades de continua-

\footnotetext{
* Recebido para publicação em junho de 1996.

** Professor Assistente de Língua e Literatura Francesas do Departamento de Letras Românicas da Faculdade de Letras da UFMG.

I A partir deste ponto Enfance será referenciado pela letra $E$, seguida pelo número da página.
}

CALIGRAMA - Belo Horizonte, 2:63-72 - novembro/1997 
ção. A memória, ou melhor, o discurso da memória, apresenta-se infinito.

Nathalie Sarraute, na primeira página da obra, mostra-nos, em forma de diálogo, seu projeto explicitamente resumido: fazer um recorte no vivido como está indicado no título - Enfance. Pela primeira vez em sua carreira de escritora, ela dá seu nome próprio à personagem e nos faz conhecer acontecimentos e lembranças assumidos como suas memórias, dando ao tex to um estatuto autobiográfico. Ela - escritora, narradora, personagem - está no centro dessa obra, simulando cenas, situações e frases do passado, às vezes banais, tênues ou engraçadas, às vezes graves, dolorosas e tristes.

Se, pela primeira vez, ela fala de si mesma, o que a narradora nos apresenta é, porém, uma criança, personagem distante da Sarraute escritora. Essa criança mantém com a narradora adulta uma aliança que se funda na palavra muito mais que nos fatos.

Embora apresente o comum dos textos de memória - a centralização em um sujeito - a narradora se vale de recursos que permitirão diferenciar seu texto: a bifurcação do sujeito de rememoração em duas vozes distîntas, autônomas, o que dá à obra um caráter dramático; e os tropismos, técnica singular, usada por Sarraute em todas as suas obras ficcionais e que será utilizada, também, no texto autobiográfico.

A palavra tropismo designa o traço estilístico mais marcante na obra da escritora e consiste nas reações específicas das personagens diante de situações, cenas e, principalmente, signos verbais. Movimentos imprecisos que, num vai-e-vem, situam umas em contato com outras ou, ao contrário, as separam. Tropismo é o mundo das personagens regido pelas palavras.

Quando abrimos Enfance, vemos que não há prefácio, nem subtítulo, nem dedicatória, nem numeração de capítulos. Na primeira página temos a impressão de que não há ninguém no comando da narrativa: travessões, duas vozes se falam; não sabemos quem são, nem o que as faz falar. São duas vozes que saem do nada, do silêncio, e que vêm à superfície da página em branco como alguém que quer respirar, para, em seguida, voltar, novamente, ao silêncio. A estrutura dialogal permite ao sujeito da enunciação bifurcar-se em duas vozes que decidem viajar juntas ao passado, 'mergulhar'2 nos tropismos da infância e construir um texto de memória. Essa bifurcação surge da necessidade de partilhar

2 O verbo usado por Sarraute é sé pencher. Segundo Brulotte, Se pencher est un des verbes les plus employés par l'auteur [...] il fait partio du rêve sarratution (rêve impossible) de complicité duelle [...] it comporte aussi une bonne dose d'umbivalence: lorsqu'il isole deux êtres d'un groupe, il instature l'enfer du secret dont les autres sont exclus; il s'associe souvent à la tension ou à l'indiscrétion; il peut encore signaler une approche menaţante on répulsive. Cf. BRULOTTE, 1990-1. p.84. 
com alguém a substância informe, porém viva e forte, da memória, e propiciar o jogo dramático dos tropismos. A presença dessas duas vozes como elemento estruturador de Enfance perturba e dá nova forma à narrativa da memória. São dois, dramaticamente, o sujeito de rememoração, no instante mesmo da enunciação: voz-narradora e voz-testemunha, que se alternam num diálogo.

A memória parece à voz-narradora un mirage, une illusion, née de mon inquétude (E, 79), sem realidade palpável. É preciso, então, outro semelhante que seja também capaz de perceber e confirmar a existência e a importância daquilo que a narradora viveu em sua infância. Daí a presença de uma testemunha para dividir, com ela, a experiência de se debruçar sobre uma parcela da sua vida. A narradora mantém-se, então, entre dois pólos: o presente da escritura, compartilhado com a voz-testemunha, e os fragmentos do passado. Ela desliza entre esses dois tempos; traz do passado para a superfície da escritura a pequena Tachok, no afã de constituir-se como sujeito da memória.

As duas vozes dizem je, narram a infância de uma personagem - a pequena Nathalie. O que resta do vivido na lembrança da voz-narradora é, principalmente, da ordem da linguagem, frases ditas e ouvidas, imagens sonoras. Falar sobre a criança torna-se fazê-la falar. A narrativa tenderá a utilizar o discurso em um sistema tal, que temos a sensação de que é a criança que está conduzindo a narrativa. A transição entre o discurso das vozes adultas e a da criança é facilitada pelo fato de que todas dizem je e de que todas falam no presente. Paradoxalmente, Enfance é um texto sem passado. Ele faz parte de um mundo todo dialogado e comentado, no presente.

Os espaços em branco entre as duas vozes funcionam como silêncios, pausas entre uma pergunta e uma resposta. É próprio do diálogo um momento de repouso, mas Nathalie Sarraute não utiliza o silêncio somente como repouso: é um momento de reflexão para as vozes e para o leitor. Há, também, um grande número de reticências e aspas que são utilizadas não somente em finais de frases, mas em todo o texto:

Ils donnent à mes phrases un certain rythme, grâce à eux elles respirent. Et aussi ils leur donnent cet aspect tâtonnant, hésitant, comme cherchant à saisir quelque chose qui à tout moment s'échappe, glisse, revient, et cet aspect haché... c'est comme des bribes de quelque chose qui déferle. Elles sont suspendues en l'air, comme cabrées devant la convention littéraire, la correction grammatical, qui les amèneraient à se figer, à s'enliser. ${ }^{3}$

Enquanto a conversação entre as duas vozes estabelece o superficial e a

3 SARRAUTE, 1972. p.1.

CALIGRAMA - Belo Horizonte, 2:63-72 - novembro/1997 
distância crítica que impede que a ilusão referencial se instale, a sub-conversação da narradora, ou da menina, apresenta a verdade interior dos tropismos e promove a fusão da voz-narradora com outras vozes. Em Enfance, as sub-conversaçōes são 'deflagrações', 'descargas', 'radiações', 'correntes', 'ondas' que transportam as 'partículas', ínfimas unidades corpusculares da linguagem, que permitem a apresentação da menina e a comunicação entre a narradora e a menina, comunicação que chega até à fusão, abolindo a distância temporal entre elas.

\section{AS FUNÇÕES DA VOZ-TESTEMUNHA}

A voz-narradora, rememorando, apresenta as sensações, as experiências vividas e seus comentários, as dores e as alegrias, as invenções e as fantasias. A voz-testemunha é a voz da lucidez, do alerta, da correção, da censura, da repreensão, do comentário crítico, da ironia, da suspeita e da reflexão: $\mathrm{E}$ também a voz da cumplicidade. A voz-testemunha é presença anônima, indeterminada, ilusória talvez, mas é aquela que chama a atenção, mobiliza a curiosidade do leitor. É através dela que transparece uma substância original, que, quando discernida, nomeada, definida pela voz-narradora, perecerá, permanecendo apenas as palavras em busca da sensação: ... ce qui m'interesse ce n'est pas l'objet mais les mouvements intérieurs qu'il déclenche. ${ }^{4}$

Oriunda do desdobramento do mesmo sujeito - um duplo da voz-narradora - a voz-testemunha só tem existência lingüística. Enquanto a voz-narradora faz o trânsito entre o rememorado e o escrito, a voz-testemunha serve como suporte da estrutura dialogal, que disfarça um monólogo interior. A cumplicidade das duas vozes especifica esta escrita da memória, na qual a voznarradora, confrontada com a voz-testemunha, procura a revelação de si através de uma exploração tropismal do passado.

O papel da voz-testemunha é, efetivamente, o de alter-ego, de coadjuvante, aquela que ajuda a voz-narradora a enfrentar os tormentos, as dúvidas, os sonhos, fazer-lhe companhia em sua solidão, apaziguando os momentos difíceis na construção da memória. Para a voz-narradora, a memória da infância é rarefeita - há mais esquecimentos que lembranças. É um buraco, facilmente invadido pela ficção. A voz-testemunha ora a impulsiona, ora a refreia a combler ce trou par un replâtrage $(\mathrm{E}, 24)$. As duas vozes são como irmãs que

4 SAPORTA, 1984. p.23. 
disputam, cochicham, se criticam, julgam, se observam, se avaliam. No geral, uma voz narra, constrói e comenta os tropismos e a outra os questiona. Mas somente no geral. Desde o princípio, anuncia-se uma estratégia de mobilidade entre as duas vozes. E a voz-testemunha, oscilando entre o controle, a escuta e a cumplicidade com a voz-narradora, marcará a especificidade da escrita memorialística da autora. ${ }^{5}$

O controle é a função mais aparente. Inicialmente, a voz-testemunha exerce seu controle sobre os fatos. Ela presta atenção aos erros e inexatidões cometidas pela voz-narradora; questiona a fidelidade da memória em relação ao vivido no gesto de rememoração. Est-il certain que cette image se trouve dans Max et Moritz? Ne vaudrait-il pas mieux le vérifier? $(\mathrm{E}, 48)$.

Algumas vezes, a voz-testemunha pede mais exatidão, mais precisão dos fatos: - Mais où était-ce? A quel propos? (E, 182). A voz-testemunha exerce seu controle, também, sobre a linguagem, se a palavra é ou não a mais apropriada, se a escolha não seria excessivamente emocional. Questiona a fidelidade das palavras em relação às sensações e sentimentos da voz-narradora:

...- Mortes, devrais-tu dire, sans avoir peur d'exagérer. (E, 113) ... De la rancune, de la réprobation... osons le dire... du mépris. (E, 127) ....-Fais attention, tu vas te laisser aller à l'emphase... (E, 166)

Enfim, o controle se dá sobre a questão da interpretação. A voz-testemunha questiona se as significações construídas pela experiência são fiéis, se condizem com a vivência: - Il est probable qu'elle s'est mal exprimée. Ce qu'elle avait sans doute voulu dire était: un enfant qui aime sa mère ne la compare jamais à personne. $(\mathrm{E}, 96)$

Essa voz de controle é fundamental, porque ela tenta impedir que a voznarradora ultrapasse a borda do real e se instale no ficcional. Ao fazer isso, ela mostra alguns problemas do gênero memorialista. A voz-testemunha tenta ajudar, ao máximo, a re-construir o que a voz-narradora realmente viveu e sentiu, sem que nada seja falsificado, aumentado nem diminuído. Ela quer que a voznarradora resgate o passado e que somente a verdade seja dita.

A segunda função é a de escuta. A voz-testemunha, funcionando como.

5 A presença das vozes em Enfance e as funçōes da segunda voz foram detectadas e analisadas por Lejeune em Paroles d'enfance. Nesse artigo o autor toma Enfance como um trabalho da escritura e reflete sobre os procedimentos utilizados por Sarraute: fragmentaçāo, montagem e diálogo, sendo que nesse último, a "voz crítica" oscila entre três posiçōes: controle, escrita e colaboração. A leitura, aqui apresentada, é tributária desse crítico, ainda que abordemos dilerentemente alguns pontos comuns. Cf. LEJEUNE, 1990-1. p.23-38.

CALIGRAMA - Belo Horizonte, 2:63-72 - novembro/1997 
um "analista", auxilia o trabalho de rememoração da voz-narradora — a "analisanda". A voz-narradora recorda o passado, a infância, induzida pela voztestemunha que intervém discretamente, amortecendo uma discussão, a força das palavras, dos tropismos, propondo uma hipótese, tenta reconstruir aquilo que foi esquecido, a partir dos traços que permaneceram fragmentados e vivos.

Essa "sessão de análise" é, claramente, percebida na passagem em que a mãe brinca de lutar com seu segundo marido e a pequena Nathalie tenta participar do jogo, tomando partido da mãe e é repelida por ambos. A voz-testemunha induz a voz-narradora a se lembrar e a produzir, sucessivamente, várias interpretações sobre o "incidente":

- Une fois pourtant... tu te rappelles...

- Crois-tu vraiment?

- Et c'est tout?

- Alors, fais un effort...

- C'est bien, continue... (E, 73-76)

Ao tentar participar da brincadeira, a menina será, necessariamente, rejeitada, coisa difícil de compreender e de aceitar. No jogo cabia apenas o casal. São quatro páginas para quebrar a resistência, para levá-la ao que ela já sabia, mas que não queria saber: ...J'étais un corps étrange... em relação ao casal. (E, 63)

Esse trabalho de "analista" da voz-testemunha assemelha-se muito à escavação do arqueólogo, analogia feita por Freud. ${ }^{6}$ Ambos extraem suas inferências dos fragmentos do passado, das lembranças valiosíssimas em si mesmas, mas, via de regra, seriamente danificadas, deformadas por fatores diversos (tempo, espaço, inserção do sujeito). Ao tentar reajuntar, recuperar, remendar os fragmentos, o arqueólogo corre o risco de falsear, de colar algo fora de seu lugar, o que não ocorre com o analista. Na construção das lembranças, a recomposição do passado, a recordação de algo perdido, esquecido e fragmentado nem sempre é possível ou, nem mesmo, é o objetivo. É o caso de Enfance. Rememorar não é restaurar o passado. A voz-narradora não consegue nada

5 Segundo Freud, os dois processos são idênticos, à exceção de que o analista tem um material mais vasto à sua disposiçāo e diferente daquele do arqueólogo. Enquanto este lida com um objeto morto, destruído, mas que está lá, o analista lida com algo que se re-constrói. A "materialidade" se faz no processo de rememoração, por meio de suplementação e combinação dos restos que, apesar de fragmentados, sobreviveram e permanecem vivos. Outra diferença é que a re-construção, para o arqueólogo, é o objetivo final de seus esforços, enquanto que para o analista ela é apenas um trabalho preliminar, visto que o que se busca é a re-constituiçāo do sujeito. Cf. FREUD, 1975, p.291-304. 
além de algumas imagens do passado. Mesmo que sejam ficções, alucinações, delírios da narradora adulta que re-cria, de-forma ou des-loca, ainda assim são as imagens fragmentadas da infância que compõem a memória. Pouco lhe importa se seu trabalho "arqueológico" transforme o que ela viveu em outra coisa. Pouco lhe importa se alguns pedaços sejam falsos, pois o importante é tentar recuperar a sensação daquilo que se perdeu. Pouco lhe importa que seu texto memorialístico seja ficcional: - Et pourtant il fallait se parler.. Que pouvait-on d'autre, quel autre moyen y avait-il de se retrouver? (E, 253).

A terceira função da voz-testemunha é a de cumplicidade. As duas vozes evidentemente, distinguem-se, mas trata-se aqui de uma fusão. Uma voz se junta à outra, sem jamais se opor. Elas conversam e acabam por, quase, falarem ao mesmo tempo. Os dois $J e$ se fundem em nous, como se as duas vozes tivessem vivido as mesmas experiências:

- Je pense que c'est avant le séjour de grand-mère que cela devrait se situer..

-Ou est-ce après?

- Non, avant... il me semble que grand-mère est venue quand tu allais entrer dans la classe du certificat d'études... (E, 24l)

Esse é um dos momentos em que é difícil distinguir as duas vozes, visto que elas enunciam o mesmo enunciado quase ao mesmo tempo e compartitham das mesmas lembranças. A voz-testemunha também chama a avó da voznarradora de Vovó. Daí a dificuldade em saber quem fala, quem é quem. Além disso, em algumas passagens, as duas vozes usam o pronome on: - On dirait même qu'on le désire, que c'est cela qu'on cherche... Na função de cumplicidade, elas dão a impressão de que uma conhece a outra mais que a si mesma, uma sabendo o que se passa no interior da outra. As duas se tornam uno, em perfeita completude.

Enquanto que nas duas primeiras funções - controle e escuta - temos, claramente, na enunciação e no enunciado, um $J e$ e um $t u$, na terceira função essa distinção perde força, quase se apaga. As duas vozes encontram-se em pequenos fragmentos comuns às duas: temos duas vozes que se parecem, que viveram as mesmas experiências. Nesses instantes, o texto perde tensão e há um momento de gozo e tranquiilidade. Quando as imagens da memória mostram-se fulgurantes e o sujeito se reconhece, se identifica e se constitui como tal.

CALIGRAMA - Belo Horizonte, 2:63-72 - novembro/1997 


\section{AS VOZES E A URDIDURA DA MEMÓRIA}

Já na primeira página do livro, a voz-testemunha duvida do gesto da voznarradora de se debruçar sobre as lembranças do passado e construir a memória da criança, da pequena Nathalie. Duvida que tal gesto possibilite o resgate do passado, crença de toda escrita de memória. A dúvida da voz-testemunha funcionará, também, como desafio à voz-narradora a fazer isso: Alors, tu vas vraiment faire ça? Évoquer tes souvenirs d'enfance [...] je me demande si ce n'est pas toujours cette même crainte... (E, 7-9). A voz-narradora aceita o desafio da voz-testemunha; acha-se capaz de evocar suas lembranças de infância: - Oui, et cette fois, on ne le croirait pas, mais c'est de toi que me vient l'impulsion, depuis un moment déjà tu me pousses... (E, 9). Assim, o desafio impulsionará a narrativa. A voz-testemunha funcionará como fio condutor, o fio de Ariadne da narrativa. Acompanhando a voz-narradora em seu percurso pelo texto e pelo passado, em sua permanência no labirinto da linguagem e da memória, a voz-testemunha ajuda a narradora a fiar, à medida quẽ penetra no labirinto da lembrança e da escrita.

O gesto de escrever seu texto de memória é análogo ao de Teseu, ao entrar no labirinto para matar o Minotauro, sabendo que corria o risco de ser aprisionado e devorado pelo monstro. A voz-narradora usa os mesmos métodos do herói. Decidida a construir suas memórias, ela entra no labirinto do passado, mesmo sabendo de todos os riscos:

... là-bas tout fluctue, se transforme, s'échappe... tu avances à tâtons, toujours cherchant, te tendant... vers quoi? qu'est-ce que c'est? Ça ne ressemble à rien... personne n'en parle... ça se dérobe, tu l'agrippes comme tu peux, tu le pousses... où? n'importe où, pourvu que ça... (E, 8)

As duas vozes decidem levar adiante o projeto de construir as imagens da memória, correndo o risco de se tornarem prisioneiras das palavras, já que estas são como barreiras, que as obrigam a permanecer no labirinto. São palavras qui s'abattent sur vous et vous enferment. $(\mathrm{E}, 122)$. Palavras que limitam, cercam, comprimem e reduzem a construção da memória. O risco de ser devorada pelas palavras - o minotauro - , de se perder, permanece, pois, uma vez no interior do labirinto, é impossível ou muito difícil encontrar a saída. Porém, o objetivo das vozes não é matar esse "monstro", mas utilizá-lo na construção de uma saída, na construção das imagens, de seus tresors: ... Vous ne pouvez pas imaginer jusqu'où, jusqu'à quels trésors cachés on est conduit quand on ose s'aventurer ainsi, tenant ce fil d'Ariane dans sa main... (FO, 96-7) 
Ao contrário de santo Agostinho, que vai ao castelo do passado e de lá extrai seus tesouros, Nathalie Sarraute entra no labirinto do passado para também encontrar seus tesouros, mas com o risco de se perder por lá.

Uma diferença entre o castelo e o labirinto, como espaços da memória, é que no castelo de santo Agostinho, as imagens são "reais", claras, nítidas, "guardadas", prontas para serem apreendidas, enquanto que no labirinto de Nathalie Sarraute, as imagens são ofuscadas, difíceis de serem apreendidas, massa informe, que precisa passar por um processo de clareamento, de discernimento, de fiação.

Em Enfance, a voz-narradora, ao tentar recuperar seus tresors cachés com palavras, encontra somente os restos do vivido, apenas traços, inscrições fragmentadas. A voz-narradora fará desses traços seus tresors com a ajuda da voztestemunha. No gesto de se debruçar sobre o passado, tentando ali resgatar o vivido, a voz-narradora faz surgir uma outra coisa: algo que será construído a partir das rasuras das imagens do passado. Assim, a voz-narradora vence o monstro - a palavra - e consegue passar pelo labirinto do passado, da memória, encontrar as imagens e compõe Enfance. Nathalie Sarraute constrói Enfan$c e$ consciente de que seu texto é elaboração escrita, ato penoso e perigoso, mas, que, ao mesmo tempo, lhe é necessário. Escrever, segundo ela, é como respirar, existir, viver, o que a impulsiona para a produção literária. ${ }^{7}$

Todo memorialista sabe que, em sua trajetória para construir um texto de memórias, encontrará obstáculos, como a imprecisão dos fạtos, a indecisão das imagens, o esquecimento e o poder da linguagem. Entretanto, a escrita tradicional do eu tenta passar-se por plena, por reveladora de verdades absolutas, camuflando essas dificuldades comuns ao gênero. Para Nathalie Sarraute, a palavra não resgata o passado, nem o eu perdido com o passar do tempo. É, justamente, nessa impossibilidade, que está a força geradora de todo seu texto. É isso que constitui a própria matéria de Enfance. Nathalie Sarraute coloca no centro da obra a vacuidade do eu, a rarefação da memória, fazendo desses vazios o assunto principal de seu texto. Se o que resta do vivido são apenas traços, inscrições fragmentadas do eu, Enfance exibe os buracos da memória, tecendo, não um pano pretensamente liso, como querem os memorialistas tradicionais, mas uma colcha de retalhos ligados entre si por tênues fios, onde cada pedaço denuncia seu próprio limite, mostrando-se como tal. A colcha de retalhos, assim como o labirinto, é esse espaço mutante, móvel, impossível de se fixar.

7 Cf. RYKNER, 1991.p.153.

CALIGRAMA - Belo Horizonte, 2:63-72 - novembro/1997 
Assim, enquanto para santo Agostinho, um sujeito íntegro, real, usa a palavra para traduzir, com facilidade, as imagens nítidas do vivido, para Nathalie Sarraute o sujeito, fendido, luta com as palavras para tentar conseguir clarear, (re)compor um pouco as imagens fragmentadas de um passado para sempre perdido.

Diferentemente do narrador de Marterau que diz: Mais je n'oserai jamais. Personne jamais n'ose cela. Ils le savent et sont bien tranquilles. Ils ne courent pas le moindre risque (M, 22), Nathalie Sarraute ousa, corre o risco de descobrir o que as palavras recobrem e escondem, produzindo um texto de memória dentro de seu projeto tropismal.

RÉSUMÉ: Étude de l'oeuvre autobiographique de Nathalie Sarraute - Enfance - où sont analysés deux aspects singuliers qui la distinguent dans le contexte des écritures de la mémoire: l'utilisation des tropismes en tant que stratégie de la mémoire et la présence d'un sujet fragmentê qui s'exhibe dans une structure à deux voix.

\section{REFERÊNCIAS BIBLIOGRÁTICAS}

SARRAUTE, Nathalie. Enfance. (Romance) Paris: Gallimard, 1983.

. Nathalie Sarraute a reponse à tous. (Ensaio) Le Figaro, Paris, fev. 1972.

SAPORTA, Marc. Portrait d'une inconnue: conversation biographique. L'Arc, Le Revest - Saint-Martin, n.95, p.5-23, 1984.

BRULOTTE, Gaetan. Le gestuaire de Nathalie Sarraute. Revue des Sciences Humaines. Lille, n.217, p.75-95, 1990-1.

LEJEUNE, Philippe. Paroles d'enfance. Revue des Sciences Humaines. Lille, n.217, p.23-38, 1990-1.

FREUD, Sigmund. Construções em análise. Trad. José Octávio de Aguiar Abreu. Rio de Janeiro: Imago, 1975. (Edição standard brasileira das obras psicológicas completas de Sigmund Freud, 23).

RYKNER, Arnaud. Nathalie Sarraute. Paris: Seuil, 1991. 206p. 